\title{
Modelling Net Radiative Measurement of Meteorological Parameters Using MERRA-2 Data in Sub-Sahara African Town
}

\author{
F. O. Aweda ${ }^{1 *}$, S. Adebayo², T. K. Samson ${ }^{3}$, I. A. Ojedokun ${ }^{1}$ \\ ${ }^{1}$ Physics and Solar Energy Programme, College of Agriculture, Engineering and Science, Bowen University, Iwo, Osun State, Nigeria \\ ${ }^{2}$ Electrical and Electronics Programme, College of Agriculture, Engineering and Science, Bowen University, Iwo, Osun State, Nig eria \\ ${ }^{3}$ Statistics Programme, Collegeof Agriculture, Engineering and Science, Bowen University, Iwo, Osun State, Nigeria
}

\section{PAPER INFO}

\section{Paperhistory:}

Received 10 January 2021

Accepted in revised form 13 April 2021

\section{Keywords:}

Air temperature

HelioClim

Net radiation

Solar radiation

\section{$\begin{array}{lllllllll}A & B & S & T & R & A & C & T\end{array}$}

In this study, the net radiation was estimated using a simplestraightforward expression proposed by different researchers, which is based on the principle of the Fourier Series Technique. The estimation of net radiation of Iwo $\left(7.6292^{\circ} \mathrm{N}, 4.1872^{\circ}\right)$ from the data collected from the archive of HelioClim satellite MERRA- 2 (i.e. global solar radiation and air temperature) was done on the real and imaginary measurements. The result of both real and imaginary radiation at maximum revealed $\left(-1.6 \times 10^{-7} \mathrm{Wm}^{-2} \mathrm{day}^{-1}\right)$ and minimum at about $\left(-2.3 \times 10^{-7} \mathrm{Wm}^{-2} \mathrm{day}^{-1}\right)$, while solar radiation and temperature revealed about $\left(440 \times 10^{-7} \mathrm{Wm}^{-2}\right)$ and $299 \mathrm{~K}$ maximum and minimum $\left(3700 \times 10^{-7} \mathrm{Wm}^{-2}\right)$ and $297.7 \mathrm{~K}$, respectively. Statistically, the result indicated that the regression coefficient of 3.959 with $t$ - statistics of 3.34 and $p<0.05$ indicates that for every $1 \mathrm{~K}$ increase in air temperature, solar radiation will increase by 3.959 , which shows that both solar radiation and temperature have a significant effect on net radiation. Therefore, the researchers concluded that Iwo had maximum real net radiation in February with months such as January, March, July, August, October and December as minimum radiation while imaginary radiation had its maximum and minimum in September and August respectively.

doi: $10.5829 /$ ijee.2021.12.02.10

\section{INTRODUCTION}

The estimated net radiation (radiative energy fluxes) at the surface of the earth is an essential parameter for the analyses of the atmospheric interaction and soil vegetation in the field of meteorology, agronomy, soil science, environmental science, civil engineering, geotechnical engineering, agricultural engineering, etc. Net radiation is the solar energy balance provided by the sun across the earth surface. This radiation is the sum of short-wave and long-wave radiation energy. This energy can be determined either by direct measurement or by calculation [1]. Jegede [2] stated that the net radiation $\mathrm{R}$ can be represented symbolically as:

$$
R=(1-r) K^{+}+L^{+}-L^{-}
$$

where $r$ is the surface reflection coefficient (albedo); $K^{+}$is the incoming solar (shortwave) radiation, and $L^{-}$is the downward and upward longwave $(\geq 3 \mu \mathrm{m})$ radiation component, respectively. As an important parameter, net radiation is used for the surface energy balance and its budget since its magnitude is directly related to the various heat fluxes [2]. Therefore, net radiation is used in an advanced (or net-generation) Gaussian air pollution dispersion model to estimate the flux of sensible heat $[3$, 4]. The usefulness of net radiation can be found in the direct measurement; i.e. net radiometer during calibration [1]. More, this calibration allows the definition of a parameter term as "Net radiometer sensitivity" [1]. The dependence of net radiation is based on some atmospheric parameters. However, there are changes over time continuously and the measurement can have a series of uncertainties [1]. Evett et al. [5] reported that even new radiometers can have an error as high as $10 \%$; while,

\footnotetext{
*Corresponding Author Email: aweda.francis@bowen.edu.ng (F. O. Aweda)
} 
Halldin and Lindroth [6] used comparative studies on net radiometer at six different measurements of each net radiometer with that of four components, they found out that net radiation which was taken as a reference also had some errors. However, for the present study, estimation of net radiation is of importance by using some meteorological data obtained from the archive of HelioClim satellite MERRA-2. In support, there is wide use of meteorological data for the investigation of soilatmospheric interactions, and high interest of different researchers for its development and calculation particularly; for net radiation determination [1]. Many formulae have been proposed by different researchers, which have been summarized into two methods. The first method relies merely on air temperature [7-11], while the second method uses air and soil surface temperature [1216]. However, for this work, Method 1 was adopted, by using air temperature collected from the archive HelioClim satellite MERRA-2 data. Method 1 was also adopted by Jegede [2] and Jensen et al. [11], which pointed out the formulae proposed by Wright and Jensen [7] and Wright [17], showing a consistency in the measurement data of Copenhagen, Denmark and Davis, California. Thereafter, Allen et al. [18] applied Method 1 in the computation of net radiation in the evaluation of crop water demands. However, Method 2 is of importance in the calculation of air emissivity. For this purpose, different models were developed [12, 19, 20]. Jegede [2] reported that net radiation can be applied as an index to classify the atmospheric stability for dispersion estimate based on the Pasquill-Gifford-Turner (P-G-T) typing schemes. Routine measurement of net radiation is made by the use of a radiometer [2]. As reported by Jegede [2], net radiation data are scarce in tropical Africa. Therefore, the need to estimate net radiation using data of solar radiation and air temperature gotten from the MERRA -2 satellite. Goutourbe et al. [21] stated that only a few data are available for the West Africa region which has been collected from major field experiments such as the HAPEX-Sahel and also by other independent studies [2224]. For this case, net radiation data are not available, and this gives room for the use of satellite data by modelling air temperature and some other constants. As proposed by Holtslag and van Ulden [25] the incoming solar radiation is estimated as a linear function of the sine of the solar elevation angle with its empirical coefficient relating to turbidity and cloud cover [26, 27]. This method of linear function was applied in this paper to estimate net radiation using solar radiation and air temperature data. Both the incoming and outgoing longwave radiation components are estimated from simplified relation utilizing solar radiation, air temperature, surface temperature, cloud cover and emissivity as inputs [28, 29]. Therefore, the estimation of net radiation can be done on a parameterized relationship [30].

$$
R=\frac{(1-r)\left(a_{1} \sin \Phi+a_{2}\right)\left(1-b_{1} N^{b_{2}}\right)+c_{1} T^{6}-\sigma T^{4}+c_{2} N}{1+c_{3}}
$$

where $\mathrm{R}$ is the net radiation, $\Phi$ is the solar elevation angle, $\mathrm{T}$ is the air temperature, $\sigma$ is the Stefan-Boltzmann's constant $\left(5.67 \times 10^{-8} \mathrm{Wm}^{-2} \mathrm{~K}^{-6}\right)$. The empirical value constant used in the above equation include: $a_{1}=$ $990 \mathrm{~W} \mathrm{~m}^{-2}, a_{2}=-30 \mathrm{~W} \mathrm{~m}^{-2}$, (Turbidity coefficient), $b_{1}=0.75, \quad b_{2}=3.4 \quad$ (Cloudiness coefficient), $c_{1}=$ $5.31 \times 10^{-13} \mathrm{Wm}^{-2} \mathrm{~K}^{-6}, c_{2}=60 \mathrm{Wm}^{-2}, c_{3}=0.25$ (surface heating coefficient), $\mathrm{N}$ is the number of days for each month. $r$ is the surface reflection albedo or canopy reflection coefficient $(r=0.23)$.

The solar altitude $\Phi$ (also called the solar elevation) can be calculated from the relation,

$$
\Phi=90-\theta_{z}
$$

where $\theta_{z}$ is the zenith angle, also called the zenith distance in degrees.

$$
\cos \theta_{z}=\sin \delta \sin \emptyset+\cos \delta \cos \emptyset \cos w
$$

$\emptyset$ is the geographic latitude of Iwo $\left(7.6333^{\circ} \mathrm{N}\right)$ in degrees, $\delta$ is the declination, the angular position of the sun at solar noon concerning the plane of the equation.

$$
\begin{aligned}
& \theta_{z}=\cos ^{-1}\left(\sin \delta \sin \emptyset+\cos \delta \cos \emptyset \cos w_{s}\right) \\
& \delta=23.45 \sin \left[\frac{360}{365}\left(d_{n}+284\right)\right]
\end{aligned}
$$

$\delta$ is the declination angle in degrees, $d_{n}$ is the day number of the year, 1 on 1 January and 365 on 31 December; February is counted as having 28 days.

$$
w_{s}=\cos ^{-1}(-\tan \emptyset \tan \delta)
$$

$w_{s}$ is the hour angle measured in degree. Moreover, this method was adopted since Iwo is located at a low latitude (Tropical areas). The empirical constant in Equation (2) as reported by Jegede [2], shows that geographical variations and their values listed above are strictly applicable only for the mid-latitude condition [30]. Therefore, air temperature data obtained from the MERRA-2 satellite for Iwo were used to estimate the net radiation with some constant quantities as reported by Jegede [2]. Also, we adopted the use of the Fourier Transform Technique to obtain a simple relationship between real and imaginary parameters as

$$
\begin{aligned}
& r(k)=\frac{R(k)-R_{\min }}{R_{\max }-R_{\min }} \\
& t(k)=\frac{T(k)-T_{\min }}{T_{\max }-T_{\min }}
\end{aligned}
$$

However, the MERRA-2 satellite does not measure the minimum and maximum data, therefore, $R_{\min }=0$, $R_{\text {max }}=1, R(k)$ is the solar radiation, $T_{\min }=0, T_{\max }=$ $1, T(k)$ is the air temperature observed. For that Equations (8) and (9) then become:

$$
\begin{aligned}
& r(k)=R \\
& t(k)=T
\end{aligned}
$$


$\mathrm{R}$ is the solar radiation and $\mathrm{T}$ is the air temperature, $\mathrm{N}$ is the last day of each month (i.e January 31 , February $28 \ldots$ ) and $\mathrm{n}$ is day number $(\mathrm{n}=1,2,3 \ldots)$

$$
\begin{gathered}
\tau_{s}=\frac{S-S_{\min }}{\Delta S} \\
\tau_{t}=\frac{T-T_{\min }}{\Delta T}
\end{gathered}
$$

where $\Delta S=S_{\text {max }}-S_{\text {min }}, \Delta T=T_{\text {max }}-T_{\text {min }}$

$\tau_{s, N}=\frac{X_{S, o}}{2}+\sum_{k=0}^{N-1} X_{S, k} \cos \frac{2 \pi n k}{N}+Y_{S, k} \sin \frac{2 \pi n k}{N}$

$\tau_{s, N}=\frac{X_{t, o}}{2}+\sum_{k=0}^{N-1} X_{t, k} \cos \frac{2 \pi n k}{N}+Y_{t, k} \sin \frac{2 \pi n k}{N}$

$\tau_{s, N}-\tau_{s, N}=\frac{X_{S, o}-X_{t, o}}{2}+\sum_{k=1}^{N-1}\left[\left(\tau_{s, k}-\right.\right.$

$\left.\left.\tau_{t, k}\right) \cos \frac{2 \pi n k}{N}+\left(Y_{s, k}-Y_{t, k}\right) \sin \frac{2 \pi n k}{N}\right]$

$\tau_{s, N}-\tau_{s, N}=\frac{X_{o}}{2}+\sum_{k=1}^{N-1}\left[X_{k} \cos \frac{2 \pi n k}{N}+\right.$

$\left.Y_{k} \sin \frac{2 \pi n k}{N}\right]$

$X_{k}=\frac{1}{N} \sum_{k=0}^{N-1}\left(\tau_{s, i}-\tau_{t, i}\right) \cos \frac{2 \pi n k}{N} ; k=0,1,2$

$Y_{k}=\frac{1}{N} \sum_{k=0}^{N-1}\left(\tau_{s, i}-\tau_{t, i}\right) \sin \frac{2 \pi n k}{N} ; k=0,1,2$

Putting Equation (16) into Equation (14) results in:

$$
\begin{aligned}
& S_{\text {real }}(n)=S_{\text {min }}+\Delta S_{N}\left\{\tau_{t, N}+\frac{X_{o}}{2}+\right. \\
& \left.\sum_{k=1}^{N-1}\left[X_{k} \cos \frac{2 \pi n k}{N}+Y_{k} \sin \frac{2 \pi n k}{N}\right]\right\} \\
& S_{\text {imag }}(n)=S_{\text {min }}+\Delta S_{N}\left\{\tau_{t, N}+\frac{X_{o}}{2}+\right. \\
& \left.\sum_{k=1}^{N}\left[X_{k} \cos \frac{2 \pi n k}{N}+Y_{k} \sin \frac{2 \pi n k}{N}\right]\right\}
\end{aligned}
$$

where, $S_{\text {real }}(n)$ and $S_{\text {imag }}(n)$ is the real and imaginary Fourier transform. Equations (7), (8) and (10) make it possible to calculate solar radiation in a specific geographic location depending on variation of ambient temperature by using data on monthly average daily solar radiation and air temperature recorded at nearest WS as reported by Kenisarin and Tkachenkova [31].

\section{METHODOLOGY}

\section{Data collection}

This study was conducted for Iwo $\left(7.6292^{0} \mathrm{~N}, 4.1872^{0}\right)$ located in the south-west region of Nigeria a sub-Sahara Africa which is in the rain forest of the region as shown in Figure 1. Average daily and monthly data of air temperature and solar radiation used in the study was obtained from the archive of the HelioClim website of soda (http://www.soda-pro.com). Based on the literature [32-36] that is, MERRA-2 meteorological re-analysis data, the as sessment of the data was extracted on the 7th July 2020. The data of twelve months for the year 2019 was obtained as the daily and monthly average for January to December 2019 in comma-separated value (CSV) data format. The choice of the twelve-month data was chosen because there was high solar radiation experienced in the year 2019. Environmental running of PYTHON code was used for data plotting and curve fittings. The statistical analysis was done using Statistical Package for Social Sciences (SPSS version 20.0). For this research, the data available are air temperature and solar radiation downloaded from the archive of the Helio Clim website. The parameter height is at $2 \mathrm{~m}$ above sea level.

\section{Statistical analysis model}

Descriptive statistics were computed for temperature and solar radiation while the Kolmogorov-Smirnov test was used to examine the normality of the data. The relationship between variables was examined using Spearman Rank Correlation while Regression Model was used to determine the effect of temperature on solar radiation. The Statistical Package for Social Sciences (SPSS version 20.0) was used to enhance data analysis.

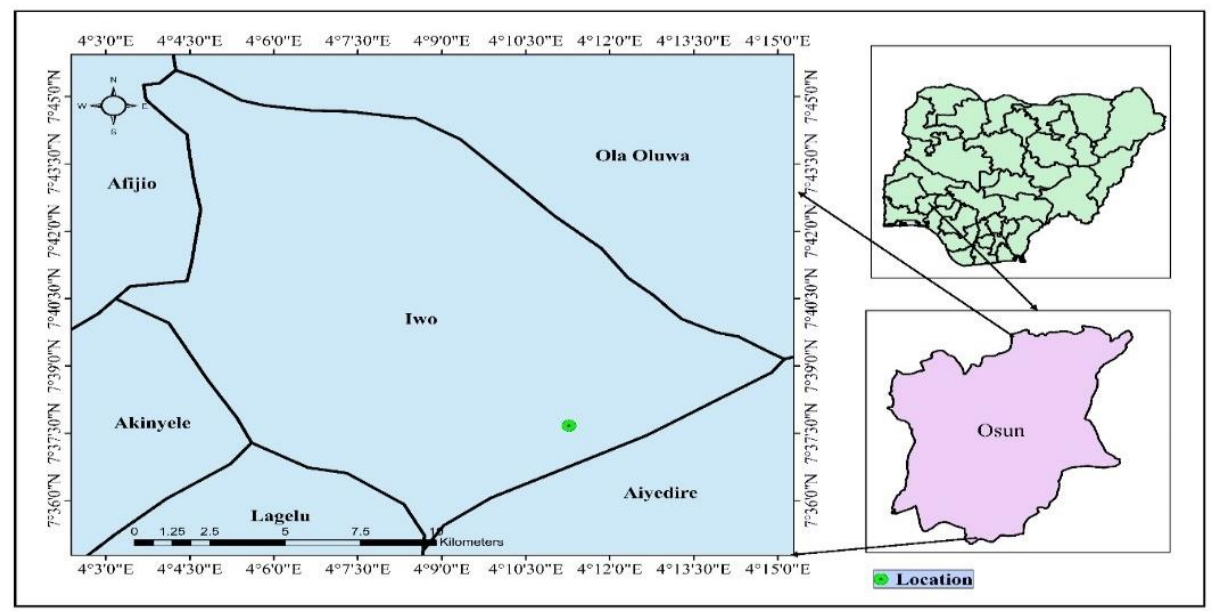

Figure 1. Map of Iwo showing the location where the data was downloaded 


\section{RESULTS AND DISCUSSION}

The data downloaded from the archive of HelioClim website MERRA-2 re-analysis Galaro et al. [36] conducted on solar radiation and air temperature, shows that the net radiation $\left(\mathrm{Wm}^{-2} \mathrm{day}^{-1}\right)$ and air Temperature (K) against months as seen in Figure $2 \mathrm{~A}$, revealed negative values which indicate that the course of air temperature (at $2 \mathrm{~m}$ ) leads above that of the net radiation which is different from what was reported by Jegede [2], where air temperature (at $5.44 \mathrm{~m}$ ) lags behind net radiation. However, the degree of the incoming solar radiation (i.e. daytime net radiation) and air temperature in the tropics is high. Therefore, as shown in Figure 2A, it is seen that the diurnal variation for both the net radiation, $\mathrm{R}$ and air temperature, $\mathrm{T}$ are periodic which confirm what was reported by Jegede [2]. As observed in Figure $2 \mathrm{~B}$, high solar radiation and air temperature were observed in April with the values $340 \mathrm{Wm}^{-2}$ and 299.5 $\mathrm{K}$, while the minimum values were observed in August for temperature $290 \mathrm{~K}$ which was due to low solar radiation recorded in Iwo. December was observed to have minimum solar radiation with the value $371 \mathrm{Wm}^{-2}$ in the year 2019; because dust in the atmosphere reduces solar radiation reaching the earth surface. However, other months such as July, October and December with the values (297.7 K, 297.8 K and 297.85 K), signify low temperature as revealed in Figure $2 \mathrm{~B}$ which is as a result of high rainfall in July and the onset of harmattan dust in October and December. The case was different with the solar radiation which was inversely proportional to the temperature in July and August $\left(430 \mathrm{Wm}^{-2}\right.$ and $431 \mathrm{Wm}^{-2}$ ) due to high rainfall recorded in July and August. Figure 2B also revealed that the more the temperature; the more the solar radiation. Vis-à-vis, the less the temperature; the less the solar radiation.

Figures $3 \mathrm{~A}$ and $3 \mathrm{~B}$ show the estimated real and imaginary net radiation observed at Iwo in 2019 using MERRA-2 re-analysis data. The result revealed high real net radiation in February to be $(-1.6 \times$ $\left.10^{-9} \mathrm{Wm}^{-2} \mathrm{day}^{-1}\right)$; with April, June, September and November averagely $\left(-2.0 \times 10^{-7} \mathrm{Wm}^{-2} \mathrm{day}^{-1}\right)$, while $\left(\approx-1.0 \times 10^{-9} \mathrm{Wm}^{-2} \mathrm{day}^{-1}\right)$ was submitted for January, March, July, August, October and December. The case is different in Figure 3B, with maximum net radiation observed in August while minimum imaginary net radiation was observed in September. As reported by Jegede [2], it is believed that the inability of Holtslag's
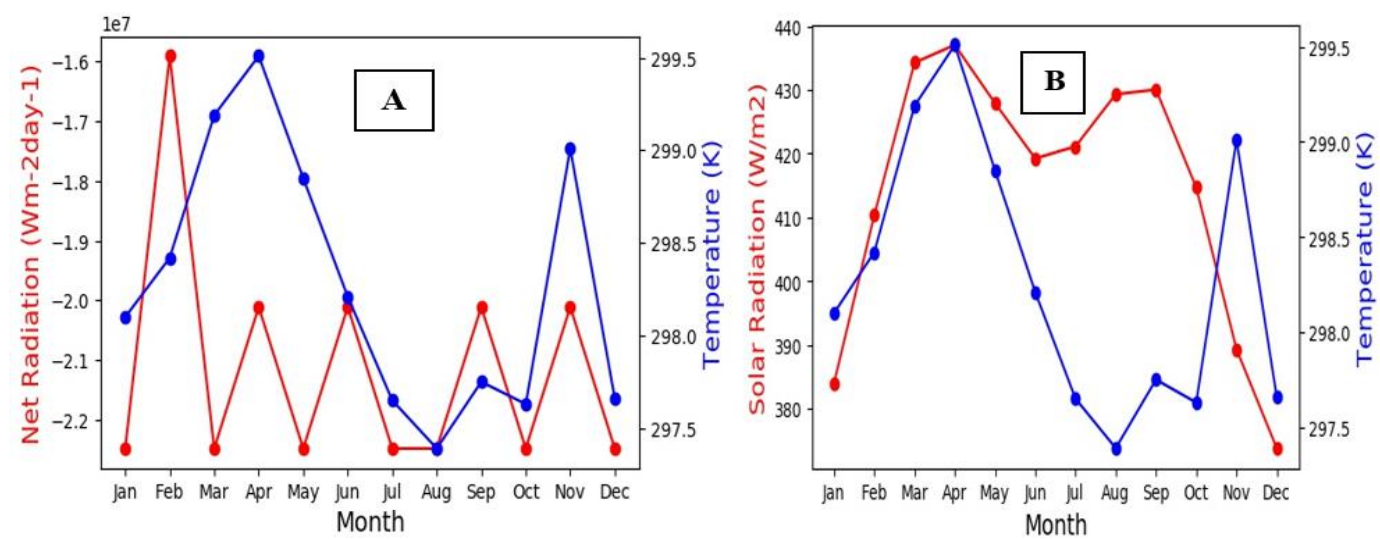

Figure 2. Monthly average of the estimated net radiation and solar radiation concerning air temperature
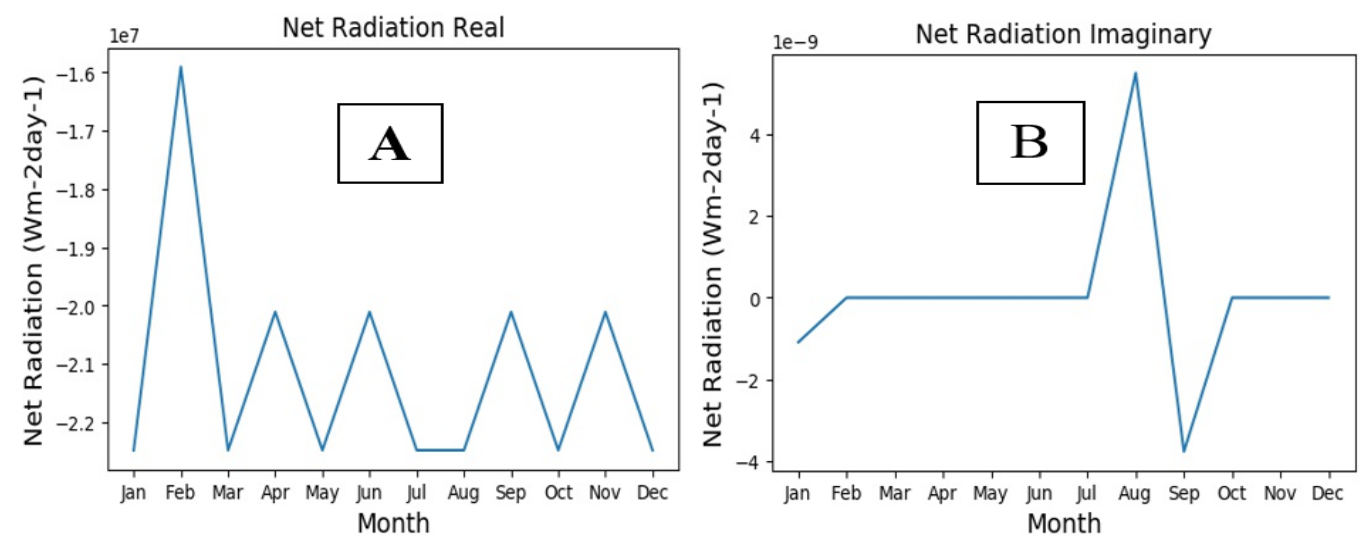

Figure 3. Monthly average of estimated real and imaginary net radiation 
scheme to reflect the observed fluctuation in the daytime net radiation values, is a result of cloud cover due to the following reasons: (1) the parameterization of $K^{+}$(in Equation (1)) is independent of the air temperature (however, it is expressed as a function of the sine of the solar elevation angle), (2) the empirical correction for the reduction of the incoming solar radiation by clouds (that is, coefficient $b_{1}$ and $b_{2}$ ) are found to be too weak to justify the strong absorption by the deep and highly humid tropical cloud. However, Holtslag's scheme is an independent variable in the estimation of the net radiation under the cloudy tropical condition [2].

Figure 3B shows the imaginary net radiation estimated. It was observed that August had the maximum variation, while September had the minimum variation with peak $4 \times 10^{-9} \mathrm{Wm}^{-2} \mathrm{day}^{-1}$ and minimum value $-4 \times 10^{-9} \mathrm{Wm}^{-2} \mathrm{day}^{-1}$. The maximum imaginary net radiation is in agreement with the solarduring August, this was in support of what was done in Osu as reported by Jegede et al. [33]. While other months were against, however, Jegede [2] reported that Holts lag's formula does not give a better estimation, both for real and imaginary values, the trend of the values is fairly constant.
The frequency distribution average of solar radiation $\left(W^{-2} \mathrm{day}^{-1}\right)$ and air temperature $(K)$ of Iwo location for 2019 are shown in Figures $4 \mathrm{~A}$ and 4B.

Figure 5 shows the annual trend of the daily maximu $\mathrm{m}$ solar and air temperature (at $2 \mathrm{~m}$ ) for Iwo. As compared with the value of net radiation, the annual solar radiation and air temperature portray double peeks which are in agreement with what was reported by Jegede [23] However, an increase in temperature occurred February and March (the hottest months of the year at the location), where the minimum temperature was recorded in January and December. However, as reported by Aweda and Samson [35] the northern part has a high-temperature difference as compared to the southern part of the country. Therefore, the mean of the daily maximu $\mathrm{m}$ temperature is $298.3 \mathrm{~K}$; it is lower in value as compared with what was reported by Jegede [23] in Osu (302.06K). Iwo, was found to be lower in temperature because the location is in the rain forest of Nigeria. This then shows that solar radiation got to its peak in February and March [34].

However, the monthly average solar radiation $\left(W^{-2}\right)$ of Iwo for January-December 2019 revealed that
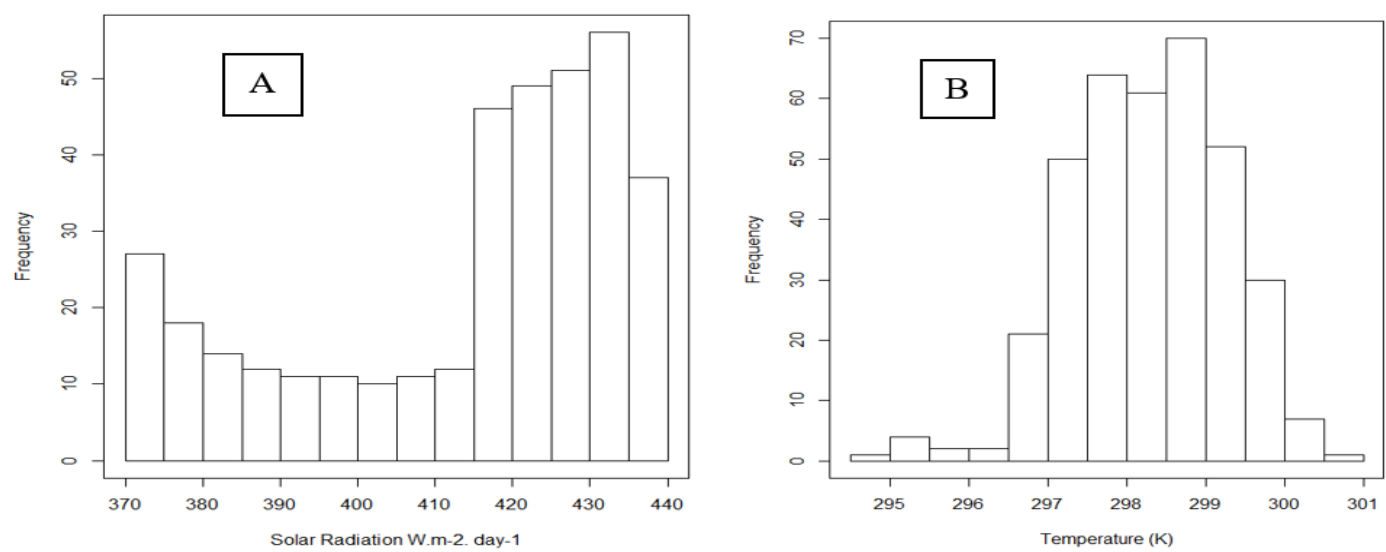

Figure 4. Histogram frequency of solar radiation in $\left(\mathrm{Wm}^{-2} \mathrm{day}^{-1}\right)$ and temperature $(\mathrm{K})$ of Iwo location for 2019
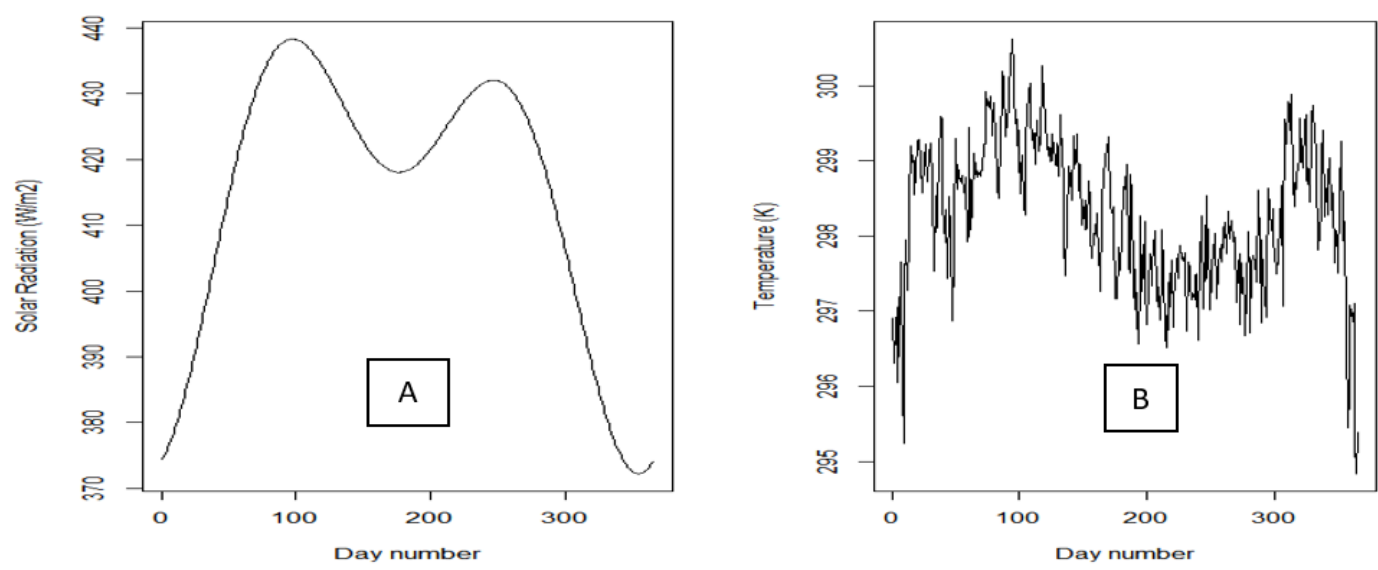

Figure 5. The daily average maximum solar and air temperature for Iwo 
January and December have the minimum values $\left(380 \mathrm{Wm}^{-2}\right.$, and $382 \mathrm{Wm}^{-2}$ respectively), while other months such as March, April, Augus t and September (MAAS) had maximum values $\left(450 \mathrm{Wm}^{-2}\right.$, and $449 \mathrm{Wm}^{-2}$ respectively) as compared with other months. The variation of solar radiation was more significant across the year; particularly, in the months of March, May, June, July, September October (MMJJSO) with an average value of about $410 \mathrm{Wm}^{-2}$.

\section{Statistical analysis}

Table 1 present a summary of descriptive statistics, the Kolmogorov- Smirnov (K-S) test for normality, correlation and regression showed that both temperature and solar radiation are negatively skewed with skewness of -0.3500 and -0.8390 , respectively meaning that both temperature and solar radiation decreased more than it increased in values within the year.
The result of the Kolmogorov- Smirnov test for the normality indicated that temperature $(\mathrm{P}$-value $=0.232)$ followed normal distribution while solar radiation was not distributed $(\mathrm{P}=0.0000)$; hence the relationship between the variables was established using nonparametric correlation. Spearman's rank correlation of 0.211 with a p-value of 0.000 was obtained which implies that there is a significant positive relationship between temperature and solar radiation meaning that the temperature increases. The result indicates that as the temperature increases significantly, there is also a corres ponding significant increase in solar radiation. The F- statistics of 13.207 was obtained with a p-value of 0.000 meaning that there is a regression relation between solar radiation and temperature. The regression coefficient of 3.959 with a t-statistics of 3.634 and $p<0.05$ indicates that for every 1 Kelvin increase in temperature, solar radiation will increase by 3.959. Therefore, the temperature has a significant effect on solar radiation.

Table1. Summary results of the descriptive statistics, Kolmogorov- Smirnov test, correlation and regression result for the impact of temperature on solar radiation

\begin{tabular}{|c|c|c|c|c|c|c|c|c|c|c|c|c|}
\hline \multirow{2}{*}{ Variables } & \multicolumn{5}{|c|}{ Descriptive statistics } & \multicolumn{2}{|c|}{ K-S } & \multirow{2}{*}{$\begin{array}{c}\begin{array}{c}\text { Correlation } \\
\text { result }\end{array} \\
\text { r- value }\end{array}$} & \multicolumn{4}{|c|}{$\begin{array}{c}\text { Summary of regression } \\
\text { summary results }\end{array}$} \\
\hline & $\mathbf{n}$ & Range & Mean & SD & Skewness & $\mathbf{Z}$ & $P$-value & & $\beta^{*}$ & F-Stat. & t-stat. & $P$-value \\
\hline Temperature & 365 & $5.78-294.84$ & 298.28 & 0.97 & -0.3500 & 1.038 & 0.232 & & & & & \\
\hline $\begin{array}{l}\text { Solar } \\
\text { radiation }\end{array}$ & 365 & $66.07-372.25$ & 414.06 & 20.56 & -0.8390 & 4.070 & 0.0000 & $0.211^{* *}$ & 3.959 & 13.207 & 3.634 & $0.0000^{* *}$ \\
\hline
\end{tabular}

\section{CONCLUSION}

This study uses the data of global solar radiation and air temperature collected from the archive of the Helio Clim satellite of MERRA-2 re-analysis to estimate net radiation of Iwo. Based on the simple procedure of the Discrete Fourier Transform Method, the net radiation of the real and imaginary month observed are maximu m (February) and minimum (September and August). Statistically, the result indicated that the regression coefficient of 3.959 with $\mathrm{t}-$ statistics of 3.34 and $\mathrm{p}<0.05$ indicates that for every $1 \mathrm{~K}$ increase in temperature, solar radiation will increase by 3.959 , which shows that both solar radiation and temperature have a significant effect on net radiation. Therefore, the study concluded that Iwo has maximum real net radiation in February with other months such as January, March, July, August, October and December as minimum radiation while imaginary radiation has its maximum and minimum in September and August, respectively.

\section{ACKNOWLEDGEMENT}

The authors wish to express their profound gratitude to the HelioClim website, Solar Radiation Data (SODA), of MERRA-2 Meteorological Re-Analys is for the provision of data for this research.

\section{REFERENCES}

1. An, N., Hemmati, S., and Cui, Y.-J. 2017. "Assessment of the methods for determining net radiation at different time-scales of meteorological variables." Journal of Rock Mechanics and Geotechnical Engineering, 9(2), pp.239-246. https://doi.org/10.1016/j.jrmge.2016.10.004

2. O. Jegede, O. 1997. "Estimating Net Radiation from Air Temperature for Diffusion Modelling Applications in a Tropical Area." Boundary-Layer Meteorology, 85(1), pp.161-173. https://doi.org/10.1023/A:1000462626302

3. Berkowicz, R., Olesen, H. R., and Torp, U. 1986. "The Danish Gaussian Air Pollution Model (Oml): Description, Test and 
Sensitivity Analysis in View of Regulatory Applications." In Air Pollution Modeling and Its Application V (pp. 453-481). Boston, MA: Springer US. https://doi.org/10.1007/978-1-4757-9125-9_30

4. Van Ulden, A. P., and Holtslag, A. A. M. 1985. "Estimation of Atmospheric Boundary Layer Parameters for Diffusion Applications." Journal of Climate and Applied Meteorology, 24(11), pp.1196-1207. https://doi.org/10.1175/15200450(1985)024<1196:EOABLP >2.0.CO;2

5. Evett, S., Prueger, J., and Tolk, J. 2011. "Water and Energy Balances in the Soil-Plant-Atmosphere Continuum."In Handbook of Soil Sciences: Properties and Processes (pp. 1-44). CRC Press: Boca Raton, FL, USA,. Retrieved from http://citeseerx.ist.psu.edu/viewdoc/download?doi=10.1.1.453.644 $5 \&$ rep $=$ rep $1 \&$ type $=$ pdf

6. Halldin, S., and Lindroth, A. 1992. "Errors in Net Radiometry: Comparison and Evaluation of Six Radiometer Designs." Joumal of Atmospheric and Oceanic Technology, 9(6), pp.762-783. https://doi.org/10.1175/15200426(1992)009<0762:EINRCA>2.0.CO;2

7. Wrightl, J. L., Jensen, M. E., and Asce, M. 1972. "Peak water requirements of crops in southern Idaho." roceedings of the American Society of Civil Engineers, Journal of the Irrigation and Drainage Division, 98(IR2), pp.193-201. Retrieved from https://eprints.nwisrl.ars.usda.gov/id/eprint/227/1/236.pdf

8. Brutsaert, W. 1975. "The Roughness Length for Water Vapor Sensible Heat, and Other Scalars." Journal of the Atmospheric Sciences, 32(10), pp.2028-2031. https://doi.org/10.1175/15200469(1975)032<2029:TRLFWV>2.0.CO;2

9. Doorenbos, J. 1977. Guidelines for predicting crop water requirements (Vol. 24). Food and Agriculture organization (FAO) irrigation and drainage paper. Retrieved from https://ci.nii.ac.jp/naid/10012763449/

10. Weiss, A. 1982. "An Experimental Study of Net Radiation, Its Components and Prediction 1." Agronomy Journal, 74(5), pp.871874. https://doi.org/10.2134/agronj1982.0002 1962007400050024x

11. Jensen, M. E., Burman, R. D., and Allen, R. G. 1990. Evapotranspiration and Irrigation Water Requirements. American Society of Civil Engineers, New York, NY. Retrieved from https://cedb.asce.org/CEDBsearch/record.jsp?dockey=0067841

12. Brutsaert, W. 1982. Evaporation into the atmosphere: theory, history and applications. Evaporation into the Atmosphere. Springer Netherlands. https://doi.org/10.1007/978-94-017-1497-6

13. Ortega-Farias, S., Antonioletti, R., and Olioso, A. 2000. "Net radiation model evaluation at an hourly time step for mediterranean conditions." Agronomie, 20(2), pp.157-164. https://doi.org/10.1051/agro:2000116

14. Bisht, G., Venturini, V., Islam, S., and Jiang, L. 2005. "Estimation of the net radiation using MODIS (Moderate Resolution Imaging Spectroradiometer) data for clear sky days." Remote Sensing of Environment, 97(1), pp.52-67. https://doi.org/10.1016/j.rse.2005.03.014

15. Saito, H., Šmůnek, J., and Mohanty, B. P. 2006. "Numerical Analysis of Coupled Water, Vapor, and Heat Transport in the Vadose Zone." Vadose Zone Journal, 5(2), pp.784-800. https://doi.org/10.2136/vzj2006.0007

16. Cui, Y. J., Gao, Y. B., and Ferber, V. 2010. "Simulating the water content and temperature changes in an experimental embankment using meteorological data." Engineering Geology, 114(3-4), pp.456-471. https://doi.org/10.1016/j.enggeo.2010.06.006

17. Wright, J. L. 1982. "New Evapotranspiration Crop Coefficients." Journal of the Irrigation and Drainage Division, 108(1), pp.57-74. Retrieved

from https://cedb.asce.org/CEDBsearch/record.jsp?dockey=0033968

18. Allen, R. G., Pereira, L. S., and Raes, D. 1998. Crop evapotranspiration-Guidelines for computing crop water requirements, Food and Agriculture organization (FAO) irrigation and drainage paper. Retrieved from https://www.scscourt.org/complexcivil/105CV049053/volume3/1 72618e_5xAGWAx 8.pdf

19. Brunt, D. 1932. "Notes on radiation in the atmosphere. I." Quarterly Journal of the Royal Meteorological Society, 58(247), pp.389-420. https://doi.org/10.1002/qj.49705824704

20. Idso, S. B. 1981. "A set of equations for full spectrum and 8 - to 14 $\mu \mathrm{m}$ and 10.5- to 12.5- $\mu \mathrm{m}$ thermal radiation from cloudless skies." Water Resources Research, 17(2), pp.295-304. https://doi.org/10.1029/WR017i002p00295

21. Goutorbe, J.-P., Lebel, T., Tinga, A., Bessemoulin,P., Brouwer, J., Dolman, A. J., Engman, E. T., Gash, J. H. C., Hoepffner, M., Kabat, P., Kerr, Y. H., Monteny, B., ... Wallace, J. S. 1994. "HAPEXSahel: a large-scale study of land-atmosphere interactions in the semi-arid tropics." Annales Geophysicae, 12(1), pp.53-64. https://doi.org/10.1007/s00585-994-0053-0

22. Wallace, J. S., Gash, J. H. C., and Icrisat, M. V. K. S. 1990. "Preliminary measurements of net radiation and evaporation over bare soil and fallow bushland in the Sahel." International Joumal of Climatology, 10(2), pp.203-210. https://doi.org/10.1002/joc.3370100207

23. Jegede, O. O. 1997. "Diurnal variations of net radiation at a tropical station? Osu; Nigeria." Theoretical and Applied Climatology, 58(3-4), pp.161-168. https://doi.org/10.1007/BF00865016

24. Jegede, O. O. 1997. "Daily averages of net radiation measured at Osu, Nigeria in 1995." International Journal of Climatology, 17(12), pp.1357-1367. https://doi.org/10.1002/(SICI)10970088(199710)17:12<1357::AID-JOC195>3.3.CO;2-3

25. Holtslag, A. A. M., and Van Ulden, A. P. 1983. "A Simple Scheme for Daytime Estimates of the Surface Fluxes from Routine Weather Data." Journal of Climate and Applied Meteorology, 22(4), pp.517-529. 0450(1983)022<0517:ASSFDE >2.0.CO;2

26. Collier, L. R., and Lockwood, J. G. 1974. "The estimation of solar radiation under cloudless skies with atmospheric dust." Quarterty Journal of the Royal Meteorological Society, 100(426), pp.678681. https://doi.org/10.1002/qj.49710042614

27. Kasten, F., and Czeplak, G. 1980. "Solar and terrestrial radiation dependent on the amount and type of cloud." Solar Energy, 24(2), pp.177-189. https://doi.org/10.1016/0038-092X(80)90391-6

28. Paltridge, G. W., and Platt, M. R. 1976. "Radiative Processes in Meteorology and Climatology." Radiative process in meteorology and climatology, 5. Retrieved from http://pascalfrancis.inist.fr/vibad/index.php?action=getRecordDetail\&idt=PAS CAL7730074104

29. Arnfield, A. J. 1979. "Evaluation of empirical expressions for the estimation of hourly and daily totals of atmospheric longwave emission under all sky conditions." Quarterly Journal of the Royal Meteorological Society, 105(446), pp.1041-1052. https://doi.org/10.1002/qj.49710544620

30. Holtslag, A. A. M. 1987. Surface fluxes and boundary layer scaling: models and applications. PhD thesis, All Wageningen University, 151, Natuur- en weerkunde,. Retrieved from https://edepot.wur.n1/203009

31. Kenisarin, M., and Tkachenkova, N. 1992. "Estimation of solar radiation from ambient air temperature." Applied Solar Energy, 28(4), pp.66-70. Retrieved from https://pascalfrancis.inist.fr/vibad/index.php?action=getRecordDetail\&idt=3830 890

32. Baumgartner, J., Höltinger, S., and Schmidt, J. 2018. "Evaluation of technical modelling approaches for data pre-processing in machine learning wind power generation models." Geophysical Research Abstracts, 20, pp.2018-14305. Retrieved from https://ui.adsabs.harvard.edu/abs/201 8EGUGA..2014305B/abstrac

33. Jegede, O. O., Ogolo, E. O., and Aregbesola, T. O. 2006 
"Estimating net radiation using routine meteorological data at a tropical location in Nigeria." International Journal of Sustainable Energy, 25(2), pp.107-115. https://doi.org/10.1080/14786450600593261

34. Aweda, F. O., Oyewole, J. A., Fashae, J. B., and Samson, T. K 2020. "Variation of the Earth's Irradiance over Some Selected Towns in Nigeria." Iranian (Iranica) Journal of Energy and Environment, 11(4), pp.301-307. https://doi.org/10.5829/IJEE.2020.11.04.08

35. Aweda, F. O., and Samson, T. K. 2020. “Modelling the Earth's
Solar Irradiance Across Some Selected Stations in Sub-Sahara Region of Africa." Iranian (Iranica) Journal of Energy and Environment, 11(3), pp.204-211. https://doi.org/10.5829/IJEE.2020.11.03.05

36. Gelaro, R., McCarty, W., Suárez, M. J., Todling, R., Molod, A., Takacs, L., Randles, C. A., Darmenov, A., Bosilovich, M. G., Reichle, R., Wargan, K., Coy, L., Zhao, B. 2017. "The Modern-Era Retrospective Analysis for Research and Applications, Version 2 (MERRA-2)." Journal of Climate, 30(14), pp.5419-5454. https://doi.org/10.1175/JCLI-D-16-0758.1

\section{COPYRIGHTS}

(C)2021 The author(s). This is an open access article distributed under the terms of the Creative Commons Attribution (CC BY 4.0), which permits unrestricted use, distribution, and reproduction in any medium, as long as the original authors and source are cited. No permission is required from the auth ors or the publishers.

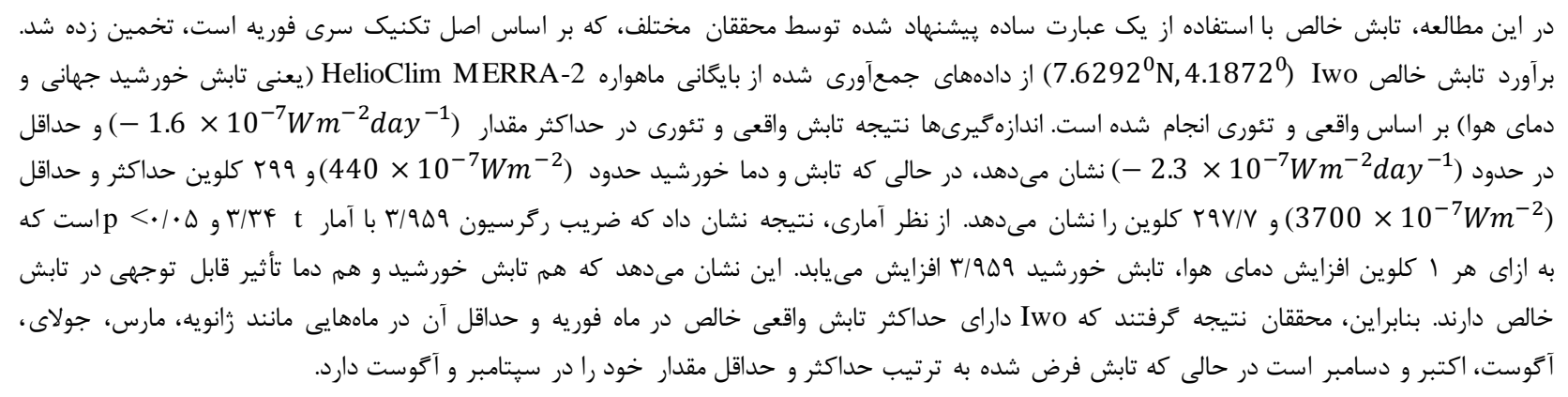

